\section{Tricodisplasia espinulosa asociada a síndrome mielodisplásico e inmunosupresión}

\author{
CRISTIÁN NAVARRETE-DECHENT ${ }^{1,2}$, CAROLINA CEVALLOS $^{1}$, \\ JUAN JORGE MANRÍQUEZ ${ }^{1}$, CLAUDIO SALAZAR ${ }^{1}$, \\ SERGIO GONZÁLEZ ${ }^{2,3}$
}

\section{Trichodysplasia spinulosa. Report of one case}

Trichodysplasia spinulosa is a rare disease that occurs in the setting of immunosuppression, associated with tolerogenic therapy used in allograft recipients or patients with hematologic malignancies. Clinically, it is characterized by a centrofacial cutaneous eruption of erythematous papules with a central keratinous spicule, often associated with variable degrees of alopecia. Histologic findings are characteristic, and electron microscopy reveals the presence of trichodysplasia spinulosa associated polyomavirus. We report a 47-year-old woman with idiopathic autoimmune pancytopenia refractory to diverse immunosuppressant regimens, with clinical and pathologic findings compatible with the disease, in whom complementary studies were required to exclude other differential diagnoses.

(Rev Med Chile 2018; 146: 107-110)

Key words: Immunosuppression; Pancytopenia; Polyomavirus.
'Departamento de Dermatología, Facultad de Medicina, Pontificia Universidad Católica de Chile,

Santiago, Chile.

¿Unidad de Melanoma y Cáncer de Piel, Facultad de Medicina,

Pontificia Universidad Católica de Chile, Santiago, Chile.

${ }^{3}$ Departamento de Anatomía Patológica, Facultad de Medicina, Pontificia Universidad Católica de Chile, Santiago, Chile.

Trabajo no recibió financiamiento Los autores declaran no tener conflictos de interés.

Recibido el 16 junio de 2017, aceptado el 23 de enero de 2018.

Correspondencia a: Sergio González B. Departamento de Anatomía Patológica, Facultad de Medicina, Pontificia Universidad Católica de Chile, Santiago, Chile. Marcoleta 377, Piso 10, Santiago, Chile.

Teléfono: +56223543206 sgonzale@med.puc.cl

\section{L} a tricodisplasia espinulosa (TS) es una entidad clinicopatológica recientemente descrita, que ocurre en contexto de inmunosupresión, típicamente asociada con trasplante de órganos sólidos y neoplasias hematológicas. Clínicamente, se caracteriza por la presencia de múltiples pápulas foliculocéntricas acompañadas de espículas centrales de queratina. Esta condición presenta hallazgos histopatológicos característicos con folículos pilosos de maduración anormal, asociado a hiperplasia de las células de la vaina interna de la raíz. Se ha encontrado presencia de infección viral por un miembro de la familia Poliomaviridae, el cual fue secuenciado en el año 2010 por van der Meijden et al., denominado poliomaviridae asociado a TS ${ }^{1}$. Sin embargo, su efecto patogénico es aún materia de estudio.

Esta condición es conocida en la literatura bajo una variedad de nombres, como tricodisplasia espinulosa asociada a virus, tricodisplasia de los inmunosuprimidos, displasia pilomatrix y foliculodistrofia asociada a ciclosporina. En el último tiempo ha existido un aumento de los reportes de esta patología, con diversos intentos terapéuticos, con resultados variables. A continuación, se realiza el reporte del primer caso descrito a nivel nacional.

\section{$\underline{\text { Reporte de caso }}$}

Mujer de 47 años de edad, con antecedentes familiares de primer grado de púrpura trombocitopénico idiopático e historia de anemia hemolítica autoinmune refractaria a tratamiento diagnosticada en la infancia, con rápida progresión a pancitopenia (inmunosupresión de años de evolución). Tres biopsias de médula ósea demostraron hallazgos sugerentes de un síndrome mielodisplásico. Además, la paciente presentaba antecedentes de insuficiencia renal y múltiples hospitalizaciones para manejo de neutropenia febril y anemia grave durante los últimos 5 años. Usó múltiples esquemas de tratamiento inmunosupresor con ciclosporina, micofenolato, metilprednisolona 

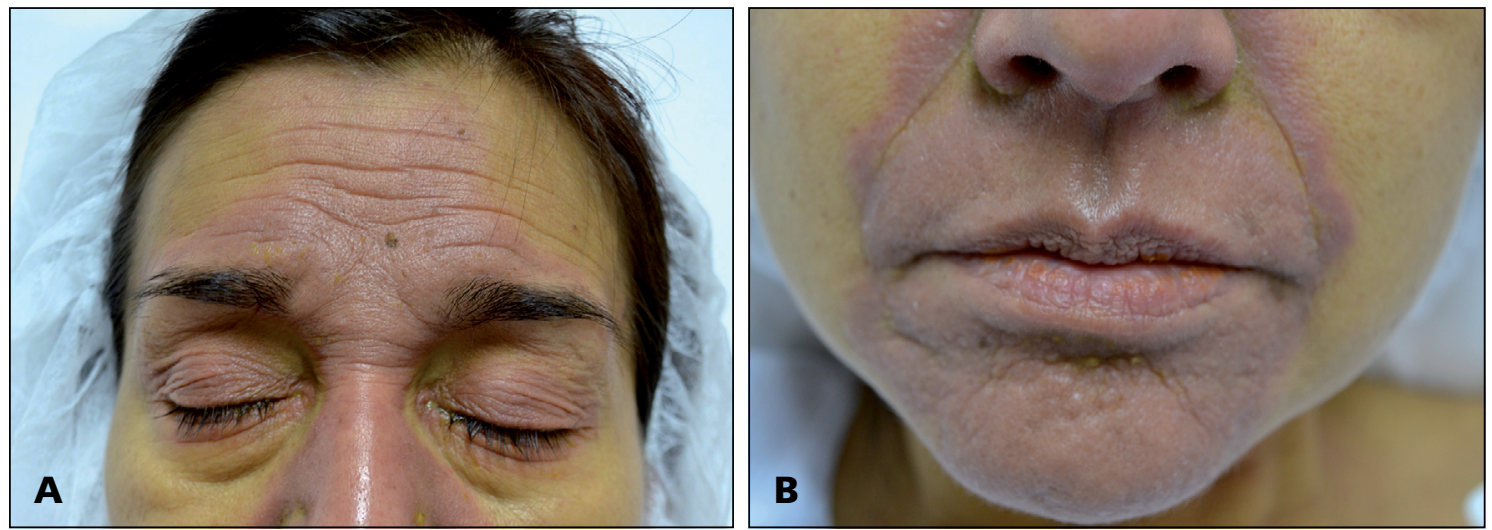

Figura 1. Tricodisplasia espinulosa. A. Placas eritematosas muy bien definidas en región centrofacial; B. Se observan pequeñas pápulas queratósicas en mentón.

y rituximab. Debido a su estado general, no se planteó la posibilidad de un trasplante de médula ósea. Al momento de la consulta, se encontraba en tratamiento con cámara hiperbárica y transfusiones de glóbulos rojos semanales. Presentaba historia de 3 meses de evolución de lesiones asintomáticas en cara, en aumento progresivo, no fluctuantes, sin lesiones en el resto del cuerpo. Al examen físico, se observaban múltiples pápulas foliculares, eritematosas, confluentes en placas en región centrofacial y en pabellones auriculares (Figura 1A y B). En los exámenes destacaba: ANA positivo en dilución 1:80 con patrón granular fino denso, anti ADN positivo dilución 1:20, negativo por Farr. Serologías VIH, virus hepatitis B y C negativas. Se sospechó un síndrome carcinoide, por lo que se solicitaron niveles de ácido 5-hidroxi-indol acético: $34,9 \mu \mathrm{mol} / 24 \mathrm{~h}$ (con límite superior normal de laboratorio en 34). Se realizó PET-CT, sin lesiones, sólo cambios inflamatorios etmoidales y maxilares bilaterales.

La biopsia de piel mostró un patrón inusual de alteración folicular, con dilatación especialmente a nivel de infundíbulo con hiperqueratosis y bulbos pilosos prácticamente ausentes (Figura $2 \mathrm{~A}-\mathrm{D}$ ) con exceso de gránulos de tricohialina y desorganización de la vaina folicular compatible con TS.

Dado los hallazgos inflamatorios sinusales del PET-CT, la paciente fue evaluada por otorrinolaringología y oftalmología, demostrándose mucormicosis invasora con compromiso de órbita. Se realizó un extenso aseo quirúrgico, con mala respuesta, evolucionando a las $24 \mathrm{~h}$ con compro- miso de órbita contralateral y extensión más allá del quiasma óptico, falleciendo a las $36 \mathrm{~h}$ desde la toma de biopsia cutánea.

\section{Discusión}

La TS fue descrita originalmente en 1999 por Haycox et al., como una infección viral foliculocéntrica en un paciente en tratamiento con ciclosporina posterior a un trasplante de riñón y páncreas ${ }^{2}$. Desde entonces, ha sido reportada bajo una variedad de nombres, invariablemente asociada a inmunosupresión, ya sea por drogas tolerogénicas en pacientes trasplantados o en contexto de neoplasias hematológicas. De acuerdo con una revisión realizada en 2011, existiría una mayor proporción de afectados de sexo masculino $(60 \%)$, con un rango edad que va entre 5 y 70 años $^{3}$.

Clínicamente se caracteriza por aparición de pápulas eritematosas o color piel con una espícula queratinocítica central, pudiendo ser asintomáticas o levemente pruriginosas. Las lesiones son de distribución principalmente centrofacial, aunque también se ha descrito compromiso extenso en tronco y extremidades. Existe, además, grado variable de alopecia, con compromiso mayoritario de cejas y pestañas. Histopatológicamente, se describen folículos pilosos de maduración anómala en fase anágena, asociado a bulbos hipertróficos y diferenciación excesiva de la vaina interna de la raíz con numerosos gránulos eosinofílicos de tricohialina e hipercornificación. En estudios con 

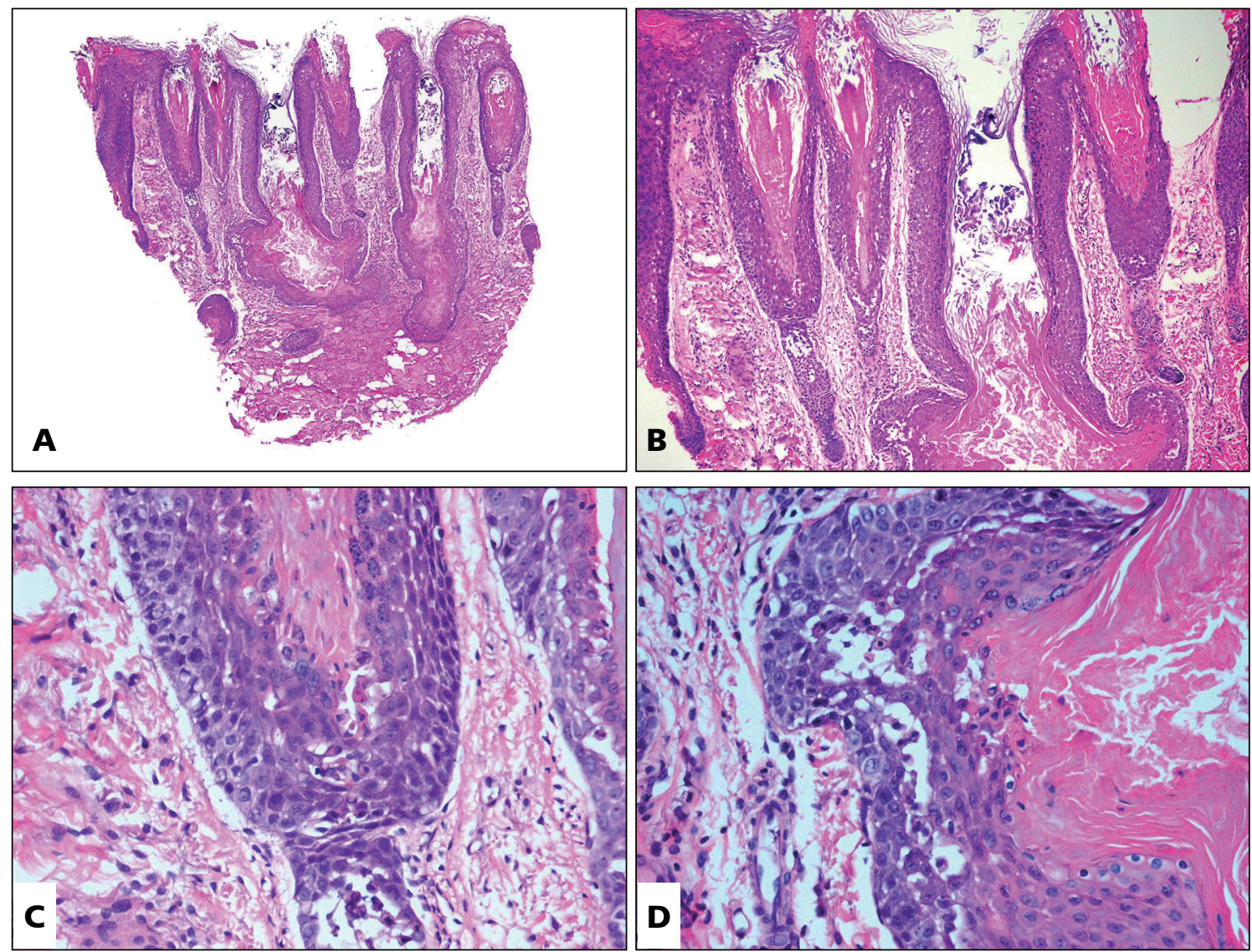

Figura 2. Hallazgos histopatológicos. A. Dilatación de infundíbulos foliculares y ausencia de bulbos; algunos folículos con atrofia sin inflamación (H\&E, 40X); B. Tapones e hiperqueratosis folicular (H\&E, 200X); C. Vaina externa con gránulos de trichohialina y disqueratosis (H\&E, 400X); D. Detalle de la ausencia de bulbos (H\&E, 400X).

microscopía electrónica se demostró la presencia de partículas virales intracelulares icosaédricas de aproximadamente $40 \mathrm{~nm}$, que corresponden a la familia Poliomaviridae ${ }^{4}$. En el año 2010 se logró amplificar y secuenciar el genoma de este nuevo poliomavirus humano nombrado poliomavirus asociado a TS (TSV, por sus siglas en inglés), desde una muestra de un paciente afectado ${ }^{1}$. La presencia de TSV puede establecer mediante amplificación del ADN viral por PCR o mediante tinción inmunohistoquímica para al antígeno mediano $\mathrm{T}$ de TSV en los gránulos de tricohialina ${ }^{5}$. A pesar de que se ha establecido una relación causal entre la infección activa por TSV y la manifestación de la enfermedad, el mecanismo fisiopatológico subyacente es aún incierto. Basándose en el efecto patológico de otros poliomavirus (por ejemplo, el poliomavirus asociado a carcinoma de células de Merkel), se ha logrado concluir que existe una inducción de la progresión del ciclo celular por el antígeno tumoral grande de TSV, mediante disrupción de las vías regulatorias de la proteína del retinoblastoma, produciendo hiperproliferación de células de la vaina interna de la raíz, lo que permitiría la replicación del ADN viral y llevaría a la formación de pápulas y espículas características de la enfermedad ${ }^{6}$.

Cabe destacar que TSV es un virus que circula comúnmente en la población general, cuya primoinfección ocurre en su mayoría en la niñez, con una seroprevalencia de alrededor de $70 \%$ en población general, mientras que, en la cohorte de inmunosuprimidos, la seroprevalencia es de casi $90 \%{ }^{7,8}$. Lamentablemente, en nuestro país no 
contamos con la PCR de TSV, por lo que no fue posible aislar el virus.

No existe un tratamiento establecido para TS, aunque se ha visto mejoría clínica con aplicación de cidofovir tópico al 1\% o 3\% (no disponible en nuestro país) y valganciclovir oral, siendo una terapia de alto costo. También podría ser efectivo el ajuste de esquema inmunosupresor en el caso de pacientes trasplantados ${ }^{9}$.

\section{Conclusión}

La TS es una entidad clínica emergente en el contexto de pacientes inmunosuprimidos, sobre todo secundario al uso de drogas imnunosupresoras, que debe ser reconocida. Su etiología más probable está ligada a la presencia del TSV. Pese a que no existe un gold standard de tratamiento para esta enfermedad, se ha intentado el uso de antivirales tópicos o sistémicos con efectividad variable.

\section{Referencias}

1. van der Meijden E, Janssens RW, Lauber C, Bouwes Bavinck JN, Gorbalenya AE, Feltkamp MC. Discovery of a new human polyomavirus associated with trichodysplasia spinulosa in an immunocompromized patient. PLoS Pathog 2010; 6 (7): e1001024.

2. Haycox CL, Kim S, Fleckman P, Smith LT, Piepkorn M, Sundberg JP, et al. Trichodysplasia spinulosa-a newly described folliculocentric viral infection in an immu- nocompromised host. J Investig Dermatol Symp Proc 1999; 4 (3): 268-71.

3. Matthews MR, Wang RC, Reddick RL, Saldivar VA, Browning JC. Viral-associated trichodysplasia spinulosa: a case with electron microscopic and molecular detection of the trichodysplasia spinulosa-associated human polyomavirus. J Cutan Pathol 2011; 38 (5): 420-31.

4. Sperling LC, Tomaszewski MM, Thomas DA. Viral-associated trichodysplasia in patients who are immunocompromised. J Am Acad Dermatol 2004; 50 (2): 318-22.

5. Wanat KA, Holler PD, Dentchev T, Simbiri K, Robertson E, Seykora JT, et al. Viral-associated trichodysplasia: characterization of a novel polyomavirus infection with therapeutic insights. Arch Dermatol 2012; 148 (2): 21923.

6. Kazem S, van der Meijden E, Wang RC, Rosenberg AS, Pope E, Benoit T, et al. Polyomavirus-associated trichodysplasia spinulosa involves hyperproliferation, pRB phosphorylation and upregulation of p16 and p21. PLoS One 2014; 9 (10): e108947.

7. Chen T, Mattila PS, Jartti T, Ruuskanen O, Söderlund-Venermo M, Hedman K. Seroepidemiology of the newly found trichodysplasia spinulosa-associated polyomavirus. J Infect Dis 2011; 204 (10): 1523-6.

8. van der Meijden E, Kazem S, Burgers MM, Janssens R, Bouwes Bavinck JN, de Melker H, et al. Seroprevalence of trichodysplasia spinulosa-associated polyomavirus. Emerg Infect Dis 2011; 17 (8): 1355-63.

9. Fischer MK, Kao GF, Nguyen HP, Drachenberg CB, Rady PL, Tyring SK, et al. Specific detection of trichodysplasia spinulosa-associated polyomavirus DNA in skin and renal allograft tissues in a patient with trichodysplasia spinulosa. Arch Dermatol 2012; 148 (6): 726-33. 